\title{
Legg-Calvé-Perthes hastalığının doğal seyri
}

\author{
Natural history of Legg-Calvé-Perthes disease
}

\author{
Şenol Bekmez, A. Mümtaz Alpaslan \\ Çankaya Ortopedi Grubu, Özel Çankaya Hastanesi Ortopedi ve Travmatoloji Departmanı, Ankara
}

LCP (Legg-Calvé-Perthes) hastalığı, sonuçta femur üst ucunda az veya çok deformite bırakarak iyileşir. LCP sonrası femur üst uçta gelişen coxa magna, coxa plana, coxa breva, sferisite kaybı, uyumsuz eklem, instabilite, trokanterik büyüme, kısalık, uyumsal asetabular displazi gibi eklem içi ve dışı deformiteler, eklem ilişkisini ve mekaniğini bozarak osteoartrit gelişimine zemin hazırlar. Kalçanın prognozunu belirleyen faktörler; hastanın yaşı, epifizin tutulum miktarı, ossifik nükleusun ebadı ve tutulumun yeri olarak özetlenebilir. Perthes hastalığı sekellerinde, radyolojik osteoartrit oranı normal popülasyona göre yüksektir. Ayrıca, LCP hastalığı geçirmiş olanlarda dördüncü dekad sonrası osteoartritin süratle ivme kazandığı bilinmektedir.

Anahtar sözcülkler: Perthes hastalığı; doğal seyir, sekonder osteoartrit
LCP (Lego-Calve-Perthes) disease almost always results with various degrees of deformity in proximal femur. Several intra- and extraarticular deformities such as coxa magna, coxa plana, coxa breva, loss of sphericity, joint incongruency, instability, trochanteric overgrowth, shortening, and acetabular dysplasia may diminish joint congruency and biomechanics which precipitate osteoarthritis. Prognostic factors are age, size and location of epiphyseal involvement, and size of the ossific nucleus. In Perthes sequela, prevalance of radiological osteoarthritis is higher than normal population. In addition, progression of osteoarthritis accelerates after fourth decade in patients with LCP disease.

Key words: Perthes disease; natural history; secondary osteoartritis
egg-Calvé-Perthes (LCP) hastalığı, femur başı epifizinin vasküler beslenmesinin bozulması sonucu epifizin bir kısmı veya tamamında avasküler nekroz gelişimidir. ${ }^{[1,2]}$ Histolojik çalışmalarda, femur başı epifizinde iskemik hasara bağlı doku nekrozu gösterilmiştir. ${ }^{[3]}$ İmmatür memeli hayvanlarda femur başı kanlanmasının iyatrojenik olarak bozulduğu deneysel çalışmalarda, LCP hastalığında görülen radyolojik ve histolojik değişikliklerin benzeri oluşturulmuştur. ${ }^{[4]}$ Ayrıca, LCP hastalarında yapılan selektif anjiyografi, sintigrafi ve manyetik rezonans görüntüleme çalışmalarında, lateral epifizeal arterin orijinine yakın bölümünde oklüzyon geliş̧tiği gösterilmiştir. ${ }^{[5-7]}$

Femur başının kanlanması durdurulduğunda meydana gelen iskemik nekrozun neden olduğu ilk histolojik değişiklikler; kemik iliğinde yaygın hücre apoptozu, kemik iliği stromasında düzensizlik ve trabeküler kemikte osteoblast kaybı olarak özetlenebilir. ${ }^{\left[{ }^{8]}\right.}$
Avasküler nekrozun klasik bulgusu olan boş kemik lakunaları, birkaç hafta sonra aşikar hale gelir. İmmatür femur başındaki eklem kıkırdağının derin katmanının beslenmesi subkondral damarlar yolu ile olduğundan, kemik nekrozunun yanı sıra, sekonder ossifikasyon merkezini çevreleyen kıkırdak tabakada da hücre ölümü gerçekleşir. ${ }^{[9]}$

Ancak, LCP hastalı̆̆, kendini sınırlayan bir hastalıktır. Femur başının vasküler dolaşımı zamanla kendiliğinden yeniden oluşur. Yeniden kanlanma iki yolla olur. ilk önce haftalar içerisinde tıkanık damarlar rekanalize olur. Yapılan bir çalışma, bu yolla oluşan yeniden kanlamanın daha dar bir bölgeden ve daha kısıtlı miktarda olduğunu ortaya koymuştur. ${ }^{[10]}$

Daha sonra, aylar içerisinde femur başını besleyen yeni damarlar gelişir. Yeniden kanlanma ile birlikte nekrotik kemik rezorbe olarak yerine inflamatuvar hücreler, fibroblast-benzeri hücreler ve osteoklastlardan

- Illetişim adresi: Dr. Şenol Bekmez, Özel Çankaya Hastanesi, Ortopedi ve Travmatoloji Departmanı, Bülten Sok. No: 44 Kavaklıdere, Ankara Tel: 0312 - 4261450 e-posta: drsenolbekmez@gmail.com

- Geliș tarihi: 20 Șubat 2017 Kabul tarihi: 20 Șubat 2017 
zengin fibrovasküler bir doku birikir. Yeniden kanlanan bölgelerdeki osteoklast aracılı rezorpsiyonun baskın hale gelişiyle, kemik yapım ve yıkımı arasındaki denge kemik yıkımı lehine bozulur. ${ }^{[9]}$

Sonuçta, 2-4 yıllık bir zaman zarfinda nekrotik avasküler dokular rezorbe olarak normal kemik dokusu ile yer değiştirirken, femur başı epifiz, fizis ve metafizi ile asetabulumda birtakım karakteristik değişiklikler meydana gelmektedir. ${ }^{[10-12]}$ Sonuç olarak, LCP hastalığı femur başında az veya çok deformite bırakarak iyileşir.

\section{EPIFIZDEKI DEĞişiKLiKLER}

Femur başı epifizinde belirli bölgelerde nekrotik kemik osteoklastlar aracılığıla rezorbe olur ve oluşan boşluk osteoblastlar tarafindan oluşturulan yeni kemik dokusu ile doldurulur. Bu süreç 'creeping substitution' olarak adlandırılır. Ancak, bazı bölgelerde rezorbe alanlar önce granülasyon dokusu ile dolar. Daha sonra mevcut granülasyon dokusu, sonra kıkırdak ve en sonunda kemik dokusu ile yer değiştirir. ${ }^{[13]}$

$\mathrm{Bu}$ tamir sürecinin radyografik görüntüsü, Waldenstrom tarafından dört ayrı evrede özetlenmiştir: iskemi, fragmantasyon, rejenerasyon ve iyileşme. ${ }^{[14]}$ Birinci evrede, radyografik olarak epifiz dens ve sklerotik olarak görülür. Olguların üçte birinde subkondral çökme gözlenir. Salter ve Thompson, subkondral kırığın uzanımıyla, epifizdeki infarkt alanının büyüklüğü ve hastalığın prognozu arasında ilişki olduğunu belirtmişlerdir. ${ }^{[15]}$ Sonuçta, epifiz bir miktar yükseklik kaybederken aynı zamanda fragmantasyon başlar. Bu evrede nekrotik epizifin yerine geçen yeni kemik dokusu, deformasyonlara yatkın ve biyomekanik olarak zayıf bir dokudur. Ayrıca, eklem effüzyonu, ligamentum teres hipertrofisi ve mediyaldeki kıkırdak dokunun hipertrofisi gibi nedenlerle, femur başı anterolateral epifizinin ekstrüzyonu bu evrede gelişebilir. ${ }^{[16,17]} \mathrm{Bu}$ aşamada, biyomekanik olarak zayıf olan fragmante dokunun ekstrüzyonu ile beraber eklem kıkırdağı derin tabakalarındaki enkondral ossifikasyonun etkilenmesi sonucu, femur başında kalıcı sferisite kaybı gibi deformiteler meydana gelir. Bir sonraki aşamada, nekrotik kemiğin yerini matür lamellar kemik dokusu alır. En son evrede ise oluşan kemik yeniden şekillenir.

\section{METAFiZDEKI DEĞişiKLLIKLER}

Bazı hastalarda, hastalığının doğal seyri sırasında, metafizde osteroporoz ve büyüme plağına komşu kist oluşumu gözlenebilir. Metafizer kistler, fragmantasyon evresinde ortaya çıkar ve iyileşme döneminde tamamen kaybolur. ${ }^{[18]}$ Oluş mekanizması halen aydınlatılamamıştır. LCP hastalığında görülebilen bir diğer değişiklik, metafizde genişlemedir. Bu genişlemenin, epifizdeki ekstrüzyon, femur başındaki genişlemenin bir yansıması olduğu düşünülmektedir. ${ }^{[14]}$

\section{BÜYÜME PLAĞINDAKI DEĞişiKLIKLER}

LCP hastalığında, femur başı büyüme plağında prematür kapanma meydana gelir. Bu durum, femur boynunda büyüme bozukluğuna yol açar. Longitudinal ve apozisyonel büyümenin etkilenerek trokanter majorun normal büyümesi sonucu femur boynunu geçmesi, kalça biyomekaniğinin bozulması ve coxa plana, coxa vara, coxa breva ve coxa magna ile sonuçlanır. ${ }^{[19]}$

Histokimyasal çalışmalarda, LCP hastalarının büyüme plağı kıkırdağında kollajen ve proteoglikan içeriği azalıp, yağ inklüzyon cisimlerinin birikimi gösterilmiştir. ${ }^{[12]}$

\section{ASETABULUMDAKi DEĞişiKLiKLER}

LCP hastalığında, asetabular kıkırdakta kalınlaşma ve triradiat kıkırdağın prematür kapanması sonucu asetabulumun şekil ve derinliğinde değişiklikler gözlemlenebilir. Öte yandan, iyileşme evresi ve iskelet matüritesi arasındaki sürede, asetabulumda yeniden şekillenme oluştuğu gösterilmiştir. ${ }^{[20]}$ Femur başındaki şekil değişikliklerine asetabulum da uyum sağlayarak, yetersiz örtme gibi kapsama değişikliklerine veya ilişki uyumsuzluklarına neden olur.

\section{FEMUR BAŞI DEFORMITESININ PATOGENEZi}

LCP hastalığının seyrinde meydana gelen kemik nekrozu, femur başı ve eklem kıkırdağının mekanik direncini zayıflatır. İskemi evresinde görülen, kemikte artmış kalsiyum birikimi kırılganlığını arttırır. ${ }^{[21]}$ Nekrotik kemik osteosit ve osteoblast aktivitesi göstermediğinden, fizyolojik aktiviteyle oluşan mikro-hasarlar birikerek subkondral kırık oluşumu ile sonuçlanır. Yeniden kanlanma süreci, iskemik durumdaki kemiğin mekanik özelliklerini daha da zayıflatır. Çünkü, bu evrede kemik yapım ve yıkım arasındaki denge, belirgin şekilde kemik yıkımı lehine bozulmuştur. ${ }^{[4]}$ Deneysel çalışmalarda, hastalığın bu evresinde, bifosfonatlar aracılığıyla kemik rezorpsiyonunun inhibisyonu ile femur başının yapısındaki trabeküler kemiğin şeklinin korunabileceği gösterilmiştir. ${ }^{[22,23]}$ Ancak, bifosfonatların LCP hastalarındaki etkinliği konusunda herhangi bir klinik çalışma bulunmamaktadır.

LCP hastalığı femur başının yük taşıyan kısmını ilgilendirdiği için, femur başı deformitelerinin oluşumunda kalça eklemindeki yüklerin dağılımı da önem arz eder. Sağlıklı erişkinlerde kalça eklem kontakt basıncı, yürümekle vücut ağırlığının 2,5, koşmakla vücut 
ağırlığının 4,5 katına kadar çıkmaktadır. Çocuklar ise erişkinlere göre daha aktiftir ve daha kısa adım aralıklarıyla yürürler. ${ }^{[24]}$ LCP hastalığında femur başının mekanik olarak zayıflaması sonucu, günlük aktivitelerde oluşan fizyolojik kuvvetler deformasyona yol açar. Bazı çalışmalar, LCP hastalığında aktivite kısıtlamasının femur başı deformitesi gelişiminde koruyucu rolü olduğunu savunur. ${ }^{[25]}$

\section{DOĞAL SEYIRDE YAŞIN ETKISi}

Perthes hastalığında, hastalığın başlangıç yaşı arttıkça prognoz kötüleşmektedir. Yapılan çalışmalarda, altı yaşından küçük başlangıçlı olgularda klinik sonuçların, sekiz yaş üzerine göre daha iyi olduğu bildirilmiştir. ${ }^{[26]}$ İyileşme düzeyindeki bu farklılığın nedenleri henüz aydınlatılamamıştır. Küçük yaşlarda epifiz kemik çekirdeğinin ileri yaşlara göre küçük oluşu, nekroza uğrayan kısmın göreceli küçüklüğü ve kendisini kuşatan kıkırdağın (eklem kıkırdağı ve büyüme plağı kıkırdağı) daha kalın oluşu nedeniyle göçmenin korunması, ayrıca küçük kemik alan nekrozunun yeniden kanlanmasının daha süratli oluşmasına bağlanabilir.

Öte yandan Fabry ve arkadaşları, beş yaşından önce başlayan LCP olgularında sonuçların her zaman iyi olmadığını vurgulamıştır. ${ }^{[27]}$ Nakamura ve arkadaşları, altı yaşından küçük başlangıçı LCP hastalarında nekrotik alanın büyük olması, lateral pillar evre $C$ ve kalça eklem hareket açıklığının azalmasının, kötü prognozla ilişkili olduğunu göstermişlerdir. ${ }^{[28]}$ Yedi yaş ve üzeri başlangıçlı hastalarda femur başının ekstrüzyonu, genellikle kritik değer olarak kabul edilen \%20'den fazla olmaktadır. Joseph ve arkadaşları, 610 hastalık serilerinde femur başı ekstrüzyonunun, yedi yaşın altındaki hastalarda \%19, yedi yaşın üstündeki hastalarda ise $\% 25,6$ oranında olduğunu bildirmişlerdir. ${ }^{[14]}$

Ergenlik çağına yaklaşıldıkça, femur başı epifizinin büyüme hızı ve dolayısıyla yeniden şekillenme kapasitesinin azaldığı bilinmektedir. ${ }^{[29]}$ Başka bir çalışmada ise, adolesan çağ başlangıçlı olgularda, iyileşme evresinde revaskülarizasyon süreci tamamlanması için yeterli süre bulunmadığı vurgulanmıştır. ${ }^{[30]}$

\section{DOĞAL SEYIR}

LCP hastalığı, sonuçta femur üst ucunda az veya çok deformite bırakarak iyileşir. Ortaya çıkan rezidüel kalça deformitesi, adolesan veya erken yetişkin dönemde ilerleyici sekonder osteoartrite neden olur. LCP sonrası femur üst uçta gelişen coxa magna, coxa plana, coxa breva, sferisite kaybı, uyumsuz eklem, instabilite, trokanterik büyüme, kısalık, uyumsal asetabular displazi gibi eklem içi ve dışı deformiteler, eklem ilişkisini ve mekaniğini bozarak osteoartrit gelişimine zemin hazırlar. Ross Jr ve arkadaşları, rezidüel Perthes (26 kalça) ve Perthes benzeri ( $10 \mathrm{kalça}$ ) problemli, cerrahi güvenli çıkık uyguladıkları toplam 36 kalçada, labral patoloji oranının \%76, asetabular kondromalazi bulgusunun $\% 59$, femoral taraf kıkırdak probleminin \%81 olduğunu, Stulberg III veya yukarısı olgularda ve trokanter - baş merkezi mesafesi artışının intraartiküler patoloji riskini arttırdığını bildirmişlerdir. ${ }^{[31]}$

Femoroasetabular sıkışma sendromunda doğal seyir çalışmalarında, osteoartrit gelişiminin bu tip kalçalarda 3,7-10 kat daha yüksek olduğu gösterilmiştir. ${ }^{[32]}$

\section{TEDAVI EDILMEMIŞ OLGULARDA DOĞAL SEYIR}

LCP hastalığının doğal seyrinde, hastaların bir kısmında femur başı ve boynunda deformite ve trokanter majorda aşırı büyüme gelişir. ${ }^{[33]}$ LCP hastalığında kalçanın prognozunu belirleyen faktörler; epifizin tutulum miktarı, ossifik nükleusun ebadı ve tutulumun yeri olarak özetlenebilir. Stulberg, 171 kalçada ortalama 25-30 yıllık takipli çalışmasında, hastaları, iyileşme sonrası femur başında kalan sekelin şiddeti ve femur başı - asetabulum uyumunun derecesine göre beş gruba ayırmıştır. ${ }^{[34]}$ Buna göre, Grup I ve II kalçalarda femur başı sferik ve eklem yüzeyleri uyumlu olup, sekonder dejeneratif artrit gelişimi \%16 olarak bildirilmiştir. Grup III ve IV kalçalarda femur başı sferikliğini kaybetmiştir (ovoid), ancak çeşitli derecelerde eklem uyumu vardır. Grup III hastaların \%60'ında osteoartrit gelişmiştir. Grup V kalçalarda ise hem femur başı sferikliğinde düzleşme görülmüş hem de eklem uyumu ileri derecede bozulmuştur. Grup IV ve V'te osteoartrit oranı $\% 75$ olarak bildirilmiştir. Stulberg ve arkadaşlarının çalışmasında, tedavi edilmemiş LCP hastalarının \%45'i iyi (Grup I-II), \%22'si orta (Grup III), \%33'ü ise kötü (Grup IV-V) olarak sınıflandırılmıştır. ${ }^{[33]}$ Sonuç olarak, uzun dönem takip çalışmalarında, rezidüel Perthes ve Perthes-benzeri hastalarda orta yaş döneminde osteoartrit gelişme ihtimali $\% 20-54$ oranında verilmektedir.

Larson ve arkadaşları, konservatif tedavi edilmiş ve 20 yılın üzerinde takip süresi bulunan hastalardan oluşan çalışmalarında, sferik ve uyumlu eklem varlığında (Stulberg I ve II) sekonder osteoartrit riskinin düşük olduğunu göstermişlerdir. ${ }^{[35]}$ Öte yandan, Stulberg III, IV ve V olan hastalarda osteoartrit oranı yüksek bulunmuştur. Bu nedenle, LCP hastalığının tedavisinde sekonder dejeneratif osteoartritin önlenmesi için, sferik ve asetabulum ile uyumlu bir femur başı elde etmek hedeflenmelidir. Çok merkezli ileriye dönük çaIışmalarda, hastalığın başlangıç yaşı, lateral pillar tutulumunun derecesi ve uygulanan tedavi metodunun 
Stulberg evresi için belirleyici faktörler olduğu gösterilmiştir. ${ }^{[36,37]}$ LCP hastalığının doğal seyri ile ilgili 23 hastalık kendi deneyimimizde, ortalama 15 yıllık takip sonucunda, lateral pillar evresinin klinik sonuçlarla ilişkili olduğunu ve breys kullanımının uzun dönem sonuçlar üzerinde etkisi bulunmadığını gördük. ${ }^{[38]}$

McAndrew ve arkadaşları[ ${ }^{[35]}$ LCP hastalarının ortalama 47 yıllık sonuçlarını derledikleri çalışmalarında, 14 hastanın 15 kalçasında total kalça artroplastisi uygulandığını bildirmişlerdir (\%45). ${ }^{[39]}$ Bu oran, normal popülasyondaki kalça osteoartriti insidansından yüksektir. LCP hastalığı sekeline bağlı total kalça artroplastisi uygulamalarında, iyatrojenik sinir hasarları, ekstremitenin fazla uzatılması ve uygulama tekniğindeki zorluklar bildirilmesine rağmen sonuçlar başarılıdır. ${ }^{[40-42]}$

LCP hastalığının doğal seyir incelemesinde gözden kaçırılmaması gereken diğer bir nokta, artroplasti henüz uygulanmamış ancak problemli kalçalarda, osteoartrit seviyesi, ağrı şiddeti, günlük aktivite kısıtlanmaları ve yürüme mesafelerinin ne olduğunun da prognozu belirleyen unsurlar olduğudur. Perthes hastalığı sekellerinde, 40 yaş civarında radyolojik osteoartrit oranı $\% 50$ bulunmuştur. ${ }^{[43]}$ Ayrıca, 40 yaş sonrası osteoartritin süratle ivme kazandığı bildirilmektedir. ${ }^{[44]}$

\section{KAYNAKLAR}

1. Catterall A. The natural history of Perthes' desease. J Bone Joint Surg Br 1971;53(1):37-53.

2. Atsumi T, Yamano K, Muraki M, Yoshihara S, Kajihara T. The blood supply of the lateral epiphyseal arteries in Perthes' disease. J Bone Joint Surg Br 2000;82(3):392-8.

3. Jensen OM, Lauritzen J. Legg-Calvé-Perthes' disease. Morphological studies in two cases examined at necropsy. J Bone Joint Surg Br 1976;58(3):332-8.

4. Kim HK, Su PH. Development of flattening and apparent fragmentation following ischemic necrosis of the capital femoral epiphysis in a piglet model. J Bone Joint Surg Am 2002;84-A(8):1329-34.

5. de Sanctis N, Rega AN, Rondinella F. Prognostic evaluation of Legg-Calvé-Perthes disease by MRI. Part I: the role of physeal involvement. J Pediatr Orthop 2000;20(4):455-62.

6. Conway JJ. A scintigraphic classification of Legg-CalvéPerthes disease. Semin Nucl Med 1993;23(4):274-95.

7. Atsumi T, Yamano K, Muraki M, Yoshihara S, Kajihara T. The blood supply of the lateral epiphyseal arteries in Perthes' disease. J Bone Joint Surg Br 2000;82(3):392-8.

8. Kim HK, Stephenson N, Garces A, Aya-ay J, Bian H. Effects of disruption of epiphyseal vasculature on the proximal femoral growth plate. J Bone Joint Surg Am 2009;91(5):1149-58. Crossref

9. Kim HK, Su PH, Qiu YS. Histopathologic changes in growthplate cartilage following ischemic necrosis of the capital femoral epiphysis. An experimental investigation in immature pigs. J Bone Joint Surg Am 2001;83-A(5):688-97.

10. Shore BJ, Millis MB, Kim YJ. Vascular safe zones for surgical dislocation in children with healed Legg-Calvé-Perthes disease. J Bone Joint Surg Am 2012;94(8):721-7. Crossref
11. McKibbin B, Ralis $Z$. Pathological changes in a case of Perthes' disease. J Bone Joint Surg Br 1974;56B(3):438-47.

12. Ponseti IV, Maynard JA, Weinstein SL, Ippolito EG, Pous JG. Legg-Calvé-Perthes disease. Histochemical and ultrastructural observations of the epiphyseal cartilage and physis. J Bone Joint Surg Am 1983;65(6):797-807.

13. Catterall A, Pringle J, Byers PD, Fulford GE, Kemp HB. Perthes' disease: is the epiphysial infarction complete? J Bone Joint Surg Br 1982;64(3):276-81.

14. Joseph B, Varghese G, Mulpuri K, Narasimha Rao K, Nair NS. Natural evolution of Perthes disease: a study of 610 children under 12 years of age at disease onset. J Pediatr Orthop 2003;23(5):590-600.

15. Salter RB, Thompson GH. Legg-Calvé-Perthes disease. The prognostic significance of the subchondral fracture and a two-group classification of the femoral head involvement. J Bone Joint Surg Am 1984;66(4):479-89.

16. Joseph B. Morphological changes in the acetabulum in Perthes' disease. J Bone Joint Surg Br 1989;71(5):756-63.

17. Kamegaya M, Moriya H, Tsuchiya K, Akita T, Ogata S, Someya M. Arthrography of early Perthes' disease: swelling of the ligamentum teres as a cause of subluxation. J Bone Joint Surg Br 1989;71(3):413-7.

18. Song HR, Dhar S, Na JB, Cho SH, Ahn BW, Ko SM, Suh SW, $\mathrm{Koo} \mathrm{KH}$. Classification of metaphyseal change with magnetic resonance imaging in Legg-Calvé-Perthes disease. J Pediatr Orthop 2000;20(5):557-61.

19. Shah H, Siddesh ND, Joseph B, Nair SN. Effect of prophylactic trochanteric epiphyseodesis in older children with Perthes' disease. J Pediatr Orthop 2009;29(8):889-95. Crossref

20. Shah $\mathrm{H}$, Siddesh ND, Joseph B. To what extent does remodeling of the proximal femur and the acetabulum occur between disease healing and skeletal maturity in Perthes disease? A radiological study. J Pediatr Orthop 2008;28(7):711-6. Crossref

21. Hofstaetter JG, Roschger P, Klaushofer K, Kim HK. Increased matrix mineralization in the immature femoral head following ischemic osteonecrosis. Bone 2010;46(2):37985. Crossref

22. Kim HK, Randall TS, Bian H, Jenkins J, Garces A, Bauss F. Ibandronate for prevention of femoral head deformity after ischemic necrosis of the capital femoral epiphysis in immature pigs. J Bone Joint Surg Am 2005;87(3):550-7.

23. Little DG, McDonald M, Sharpe IT, Peat R, Williams $P$, McEvoy T. Zoledronic acid improves femoral head sphericity in a rat model of Perthes disease. J Orthop Res 2005;23(4):862-8.

24. Song KM, Bjornson KF, Cappello T, Coleman K. Use of the StepWatch activity monitor for characterization of normal activity levels of children. J Pediatr Orthop 2006;26(2):245-9.

25. Kuroda $T$, Mitani $S$, Sugimoto $Y$, Asaumi $K$, Endo $H$, Akazawa $\mathrm{H}$, Nakagomi T, Ozaki T. Changes in the lateral pillar classification in Perthes' disease. J Pediatr Orthop B 2009;18(3):116-9. Crossref

26. Rosenfeld SB, Herring JA, Chao JC. Legg-Calvé-Perthes disease: a review of cases with onset before six years of age. J Bone Joint Surg Am 2007;89:2712-22.

27. Fabry K, Fabry G, Moens P. Legg-Calvé-Perthes disease in patients under 5 years of age does not always result in a good outcome. Personal experience and meta-analysis of the literature. J Pediatr Orthop B 2003;12(3):222-7. 
28. Nakamura J, Kamegaya M, Saisu T, Kakizaki J, Hagiwara S, Ohtori S, Orita S, Takahashi K. Outcome of patients with Legg-Calvé-Perthes onset before 6 years of age. J Pediatr Orthop 2015;35(2):144-50. Crossref

29. Shah $\mathrm{H}$, Siddesh ND, Joseph B. To what extent does remodeling of the proximal femur and the acetabulum occur between disease healing and skeletal maturity in Perthes disease? A radiological study. J Pediatr Orthop 2008;28(7):711-6. Crossref

30. Ippolito E, Tudisco C, Farsetti P. Long-term prognosis of Legg-Calvé-Perthes disease developing during adolescence. J Pediatr Orthop 1985;5(6):652-6.

31. Ross JR, Jeffrey JN, Baca G, Schoenecker PL, Clohisy JC. Intraarticular abnormalities in residual Perthes and Perthes-like hip deformities. Clin Orthop Relat Res 2012;470(11):2968-77. Crossref

32. Agricola R, Heijboer MP, Bierma-Zeinstra SM, Verhaar $\mathrm{JA}$, Weinans $\mathrm{H}$, Waarsing JH. Cam impingement causes osteoarthritis of the hip: a nationwide prospective cohort study (CHECK). Ann Rheum Dis 2013;72(6):918-23. Crossref

33. Saito $S$, Takaoka K, Ono K, Minobe $Y$, Inoue A. Residual deformities related to arthrotic change after Perthes' disease. A long-term follow-up of fifty-one cases. Arch Orthop Trauma Surg 1985;104(1):7-14.

34. Stulberg SD, Cooperman DR, Wallensten R. The natural history of Legg-Calvé-Perthes disease. J Bone Joint Surg Am 1981;63(7):1095-108.

35. Larson AN, Sucato DJ, Herring JA, Adolfsen SE, Kelly DM, Martus JE, Lovejoy JF, Browne R, Delarocha A. A prospective multicenter study of Legg-Calvé-Perthes disease: functional and radiographic outcomes of nonoperative treatment at a mean follow-up of twenty years. J Bone Joint Surg Am 2012;94(7):584-92. Crossref
36. Herring JA, Kim HT, Browne R. Legg-Calvé- Perthes disease. Part II: prospective multicenter study of the effect of treatment on outcome. J Bone Joint Surg Am 2004;86-A(10):2121-34.

37. Wiig $O$, Terjesen $T$, Svenningsen $S$. Prognostic factors and outcome of treatment in Perthes' disease: a prospective study of 368 patients with five-year follow-up. J Bone Joint Surg Br 2008;90(10):1364-71. Crossref

38. Aksoy MC, Caglar O, Yazici M, Alpaslan AM. Comparison between braced and non-braced Legg-Calvé-Perthes-disease patients: a radiological outcome study. J Pediatr Orthop B 2004;13(3):153-7.

39. Mc Andrew MP, Weinstein SL. A long-term follow-up of LeggCalvé-Perthes disease. J Bone Joint Surg Am 1984;66(6):860-9.

40. Seufert CR, McGrory BJ. Treatment of arthritis associated with Legg-Calvé-Perthes disease with modular total hip arthroplasty. J Arthroplasty 2015;30(10):1743-6. Crossref

41. Baghdadi YM, Larson AN, Stans AA, Mabry TM. Total hip arthroplasty for the sequel of Legg-Calvé-Perthes disease. Clin Orthop Relat Res 2013;471(9):2980-6. Crossref

42. Traina, F, De Fine M, Sudanese A, Calderoni PP, Tassinari E, Toni A. Long-term results of total hip replacement in patients with Legg-Calvé-Perthes diseae. J Bone Joint Surg Am 2011;93(7):e25. Crossref

43. Yrjönen T. Prognosis in Perthes disease after noncontainment treatment. 106 hips followed for 28-47 years. Acta Orthop Scand 1992;63(5):523-6.

44. Onishi E, Ikeda N, Ueo T. Degenerative osteoarthritis after Perthes' disease: a 36-year follow-up. Arch Orthop Trauma Surg 2011;131(5):701-7. Crossref 